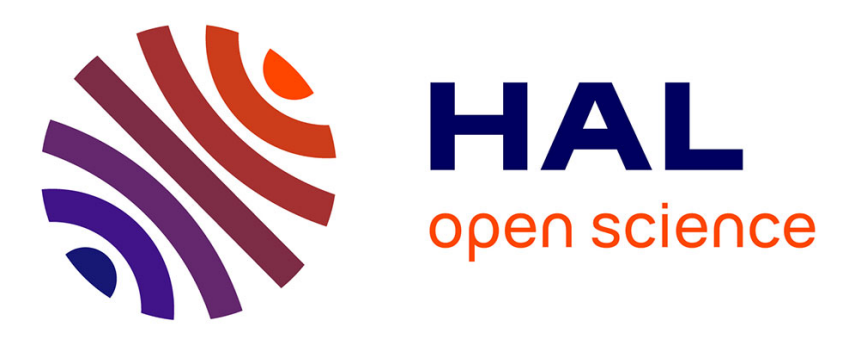

\title{
Thin films of Co1.7Fe1.3O4 prepared by radio frequency sputtering - the first step towards their spinodal decomposition
}

Thi Mai Anh Bui, Hoa Le Trong, Lionel Presmanes, Antoine Barnabé, Corine Bonningue, Philippe Tailhades

\section{To cite this version:}

Thi Mai Anh Bui, Hoa Le Trong, Lionel Presmanes, Antoine Barnabé, Corine Bonningue, et al.. Thin films of Co1.7Fe1.3O4 prepared by radio frequency sputtering - the first step towards their spinodal decomposition. CrystEngComm, 2014, n 16, pp. 3359-3365. 10.1039/c3ce42588f . hal-01067955

\section{HAL Id: hal-01067955 https://hal.science/hal-01067955}

Submitted on 25 Sep 2014

HAL is a multi-disciplinary open access archive for the deposit and dissemination of scientific research documents, whether they are published or not. The documents may come from teaching and research institutions in France or abroad, or from public or private research centers.
L'archive ouverte pluridisciplinaire HAL, est destinée au dépôt et à la diffusion de documents scientifiques de niveau recherche, publiés ou non, émanant des établissements d'enseignement et de recherche français ou étrangers, des laboratoires publics ou privés. 


\section{OATAO}

\section{Open Archive TOULOUSE Archive Ouverte (OATAO)}

OATAO is an open access repository that collects the work of Toulouse researchers and makes it freely available over the web where possible.

This is an author-deposited version published in : http://oatao.univ-toulouse.fr/ Eprints ID : 12018

To link to this article : doi: $10.1039 / \mathrm{c} 3 \mathrm{ce} 42588 \mathrm{f}$

URL : http://dx.doi.org/10.1039/c3ce42588f

To cite this version : Bui, Thi Mai Anh and Le Trong, Hoa and Presmanes, Lionel and Barnabé, Antoine and Bonningue, Corine and Tailhades, Philippe Thin films of Co1.7Fe1.3O4 prepared by radio frequency sputtering - the first step towards their spinodal decomposition. (2014) CrystEngComm ( $\left.{ }^{\circ} 16\right)$. pp. 3359-3365. ISSN 1466-8033

Any correspondance concerning this service should be sent to the repository administrator: staff-oatao@ listes-diff.inp-toulouse.fr 


\title{
Thin films of $\mathrm{CO}_{1.7} \mathrm{Fe}_{1.3} \mathrm{O}_{4}$ prepared by radio frequency sputtering - the first step towards their spinodal decomposition
}

\author{
T. M. A. Bui, ${ }^{\text {abd }}$ H. Le Trong, ${ }^{\text {abc }}$ L. Presmanes, ${ }^{a b}$ A. Barnabé, ${ }^{a b}$ C. Bonningue ${ }^{a b}$
} and P. Tailhades ${ }^{\star a b}$

Pure thin films of $\mathrm{CO}_{1.7} \mathrm{Fe}_{1.3} \mathrm{O}_{4}$ spinel iron cobaltites were prepared for the first time by radio frequency sputtering. Such films are made of small crystallites of about 20 to $30 \mathrm{~nm}$ in diameter. Because $\mathrm{CO}_{1.7} \mathrm{Fe}_{1.3} \mathrm{O}_{4}$ films have a composition located in the miscibility gap of $\mathrm{Fe}_{3} \mathrm{O}_{4}-\mathrm{CO}_{3} \mathrm{O}_{4}$, they can be submitted to spinodal transformation below about $900^{\circ} \mathrm{C}$. This transformation was also confirmed at $600{ }^{\circ} \mathrm{C}$ by $\mathrm{X}$-ray diffraction and transmission electron microscopy studies. It was demonstrated however that this spinodal transformation occurs after only a few hours at low temperature. Indeed, after annealing in air at 300 to $450{ }^{\circ} \mathrm{C}$ for a few hours, the spinodal transformation leading to two-phase spinels, one rich in iron and the other rich in cobalt, was clearly revealed by Raman spectroscopy and electrical measurements.

\section{Introduction}

Inside a miscibility gap of a phase diagram, a homogeneous solid solution is not stable. It is progressively broken down into two different phases either by nucleation and growth or spinodal decomposition. ${ }^{1}$ The first process can occur in the whole composition range of the miscibility gap and generally leads to random microstructures. The second one, which only operates in a limited area of the gap, can induce periodic microstructures at a submicronic scale. Such microstructures are particularly interesting when they contain at least a magnetic ordered phase. Giant magnetoresistance was thus observed in ferromagnetic alloys obtained from spinodal decomposition..$^{2-4}$ Other collective properties could be obtained and are used to make, for instance, magnonic crystals, the magnetic counterpart of photonic crystals. ${ }^{5,6}$ The study of spinodal decomposition of magnetically ordered phases could then be a key step in the quest for materials with original properties, which are likely to find new technological applications.

In the $\mathrm{CoFe}_{2} \mathrm{O}_{4}-\mathrm{Co}_{3} \mathrm{O}_{4}$ phase diagram, ${ }^{7-11}$ there is a miscibility gap in which spinodal decomposition can lead to regular alternation of ordered magnetic phases made of iron-rich and

Université de Toulouse, UPS-INPT, Institut Carnot CIRIMAT, 118 route de Narbonne, CEDEX 9, F-31062 Toulouse, France.E-mail: tailhade@chimie.ups-tlse.fr; Fax: +335615561 63; Tel: +33561556174

${ }^{b}$ CNRS, Institut Carnot CIRIMAT, CEDEX 9, F-31062 Toulouse, France ${ }^{c}$ Ho Chi Minh City University of Science, Vietnam National University, 227 Nguyen Van Cu Q5, 750000 Ho Chi Minh City, Vietnam

${ }^{d}$ University of Transport and Communications, Lang Thuong, Dong Da, Hanoi, Vietnam cobalt-rich spinel oxides. However, this was mainly observed in powders. ${ }^{9,13}$ Two studies were about the preparation of thin films of iron cobaltites in this range of composition and the related spinodal decomposition. ${ }^{11,12}$ Such films were obtained by the sol-gel process after annealing carried out above $800{ }^{\circ} \mathrm{C}$. In the context of potential future applications, it is however necessary to be able to prepare thin films and to induce in them spinodal decomposition at low temperatures. This work was then devoted to the preparation of thin films of iron cobaltites by radio frequency sputtering and to the study of the thermal behaviour of such films at moderate temperatures $\left(<500{ }^{\circ} \mathrm{C}\right)$.

$\mathrm{CoFe}_{2} \mathrm{O}_{4}-\mathrm{Co}_{3} \mathrm{O}_{4}$ phase diagrams have already been established experimentally $^{7-11}$ or from thermodynamic calculations. ${ }^{14}$ These phase diagrams are very similar even if there are some discrepancies in the position and the area of the miscibility gap in which two spinel phases co-exist at the thermodynamic equilibrium. The global composition $\mathrm{Co}_{1.7} \mathrm{Fe}_{1.3} \mathrm{O}_{4}$ is however close to the centreline of this region and to that of the more limited area, in which the spinodal decomposition appears. The composition $\mathrm{Co}_{1.7} \mathrm{Fe}_{1.3} \mathrm{O}_{4}$ was then chosen for this work.

\section{Experimental}

\section{Film preparation}

Pure $\mathrm{Co}_{1.7} \mathrm{Fe}_{1.3} \mathrm{O}_{4}$ was prepared by heating at $600{ }^{\circ} \mathrm{C}$ for 2 hours a mixed oxalic precursor precipitated in a hydro-alcoholic medium. After adding polyvinylic alcohol, the resulting powder was pressed inside a matrix $100 \mathrm{~mm}$ in diameter. The uniaxial pressure applied was $75 \mathrm{MPa}$. The green disc obtained was then slowly heated to eliminate the organic binder and then 
sintered at $900{ }^{\circ} \mathrm{C}$ for 12 hours. The relative density of the ceramic target thus prepared was close to $60 \%$.

Thin films were prepared by radio frequency (RF) sputtering of the previous ceramic target. The sputtering gas was pure argon and the apparatus was an Alcatel A450 equipped with a radio frequency-generator $(13.56 \mathrm{MHz})$ device as well as a pumping system (a mechanical pump coupled with a turbo molecular pump) which reaches residual pressures down to $10^{-5} \mathrm{~Pa}$, a gas flow controller, a water cooled target holder and two water cooled sample holders. The films were deposited on silicon or glass substrates. Their thickness was $300 \mathrm{~nm}$.

A residual vacuum close to $5 \times 10^{-5} \mathrm{~Pa}$ was reached in the sputtering chamber before introducing the argon deposition gas. The target was sputtered for 20 hours at the beginning. The target was also sputtered for 10 minutes before each film deposition on the substrate. The sputtering conditions (RF power and argon pressure) have been optimized to obtain pure $\mathrm{Co}_{1.7} \mathrm{Fe}_{1.3} \mathrm{O}_{4}$ spinel films.

\section{Characterization}

Structural characterization of films was performed at room temperature by grazing angle X-ray diffraction $\left(\alpha=1^{\circ}\right)$ using a Siemens D5000 diffractometer equipped with a Bruker Sol-X detector. In situ high-temperature XRD data were collected in the Bragg-Brentano $\theta-\theta$ geometry using a Bruker D8 Advanced diffractometer equipped with an Anton Paar HTK 1200N heating chamber and a Bruker LynxEye position sensitive detector. XRD patterns were recorded under air every $50{ }^{\circ} \mathrm{C}$ from 50 to $900{ }^{\circ} \mathrm{C}$ with a data collection time of 20 min per scan and a $30{ }^{\circ} \mathrm{C} \mathrm{min}^{-1}$ heating rate. The films used for these experiments were $300 \mathrm{~nm}$ thick and deposited on a pure silicon substrate because this material can withstand up to $900{ }^{\circ} \mathrm{C}$ despite low oxidation of the surface not covered by the cobaltite. The copper $K \alpha$ X-ray radiation $\left(K_{\alpha 1}=0.15405 \mathrm{~nm}\right.$ and $K_{\alpha 2}=$ $0.15443 \mathrm{~nm}$ ) was used for both diffractometers.

Imaging and elemental analyses were performed using a JEOL 2100F field emission gun transmission electron microscope (FE-TEM) operating at $200 \mathrm{kV}$ and equipped with an $\mathrm{X}$-ray energy dispersive spectroscopy (X-EDS) system. X-EDS chemical composition mapping was also performed in scanning TEM (STEM) mode. For the cross-section TEM and STEM observations, the thin films were deposited on a silicon substrate, cut into thin slices normal to the interfaces which were glued together between spacers and finally ion milled to perforation.

Raman spectra were collected under ambient conditions using a LabRAM HR 800 Jobin Yvon spectrometer with a $633 \mathrm{~cm}^{-1} \mathrm{Ar}^{+}$ion laser. Spectra acquisition was carried out for 400 seconds using a $\times 100$ objective lens and $600 \mathrm{~g} \mathrm{~mm}^{-1}$ grating. During the measurement, the resulting laser power at the surface of the sample was adjusted to $0.7 \mathrm{~mW}$. Examination of multiple spots showed that the samples were homogeneous. The substrate chosen was a quartz microscope slide able to be heated up to $600{ }^{\circ} \mathrm{C}$ without damage. Unlike silicon, this substrate has no Raman signal in the spectral range analysed.
The magnetic properties were measured in the plane of the films using a vibrating sample magnetometer Versalab Free from Quantum Design. The maximal applied field for the measurements was $30 \mathrm{kOe}$. The magnetization of the samples was corrected for substrate contribution.

Film thicknesses were measured using a Dektak 3030ST mechanical profilometer. Atomic force microscopy (AFM) was carried out using a Veeco Dimension 3000 atomic force microscope. The microstructure of the samples was also investigated by scanning electron microscopy using a JEOL JSM 6700F apparatus.

\section{Results and discussion}

\section{As-deposited films}

The nature of the phases obtained after RF sputtering depends on the preparation conditions. The RF power density has a strong influence, as revealed in Fig. 1. For a RF power close to $40 \mathrm{~W}$ and an argon pressure of $0.5 \mathrm{~Pa}$, the film is made of mixed cobalt-iron monoxide. This phase seems pure because all of the diffraction peaks can be ascribed to the XRD pattern of cobalt-iron monoxide. Moreover, the magnetization $(M)$ versus magnetic field $(H)$ curves do not display hysteresis that could reveal an extra ferrimagnetic spinel phase. When the RF power density is decreased, the X-ray diffraction pattern of a spinel phase replaces the previous pattern (Fig. 1). Some changes in the (220) peak intensity are observed for samples containing a little monoxide. These changes cannot be attributed to changes in cationic distributions because the very small differences in the electronic densities of the $\mathrm{Co}^{2+}$, $\mathrm{Co}^{3+}$ and $\mathrm{Fe}^{3+}$ ions cannot produce such large variations in the XRD peak intensity. The reason for these changes seems rather related to crystallite growth in a preferred direction.

The $M=\mathrm{f}(H)$ curves are clearly hysteresis curves for these samples as shown in Fig. 2 for the film deposited at $20 \mathrm{~W}$. The coercive force is very high at $150 \mathrm{~K}$ (close to $12 \mathrm{kOe}$ ) but decreases down to $3.6 \mathrm{kOe}$ at room temperature. This

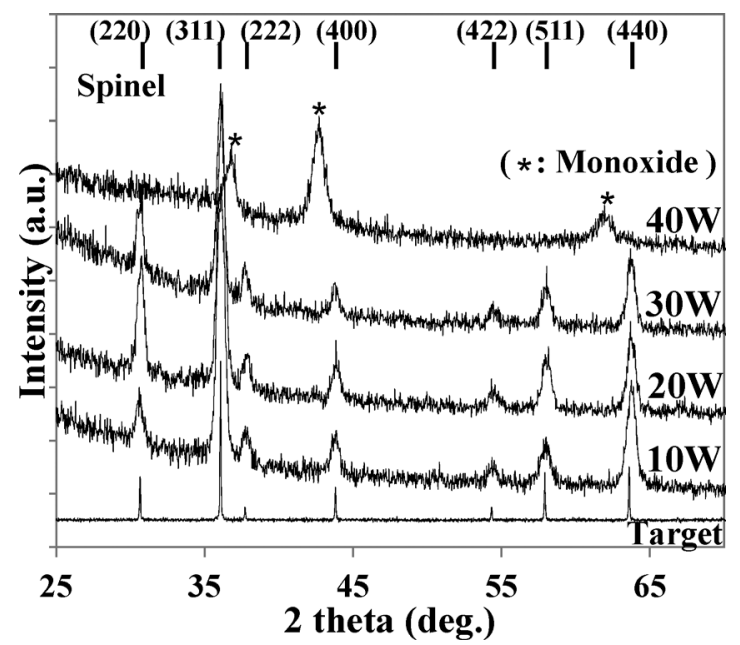

Fig. 1 X-ray diffraction patterns of films deposited at a $0.5 \mathrm{~Pa}$ argon pressure at different RF powers. 


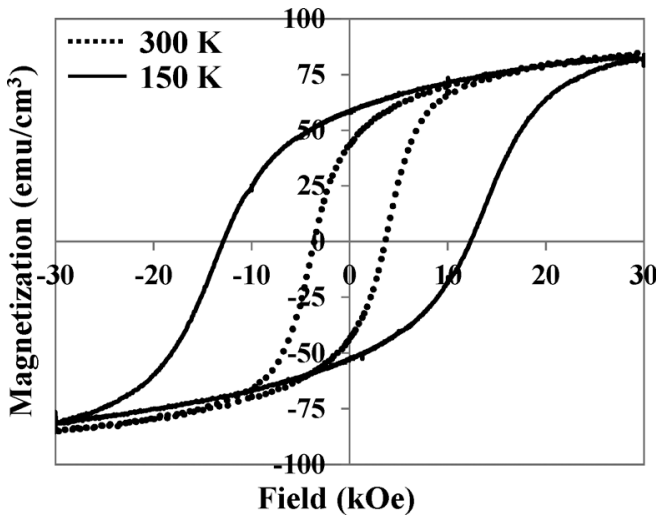

Fig. 2 Hysteresis loops registered at $150 \mathrm{~K}$ and $300 \mathrm{~K}$ of films deposited at $0.5 \mathrm{~Pa}$ and $20 \mathrm{~W}$.

behaviour, due to high magnetocrystalline anisotropy strongly dependent on temperature, is similar to that observed by Takahashi and Fine..$^{15}$ Slightly lower magnetization at $30 \mathrm{kOe}$ is observed for the film prepared at $30 \mathrm{~W}$. This magnetization is only $72.8 \mathrm{emu} \mathrm{cm}^{-3}$, which is close to 82.6 and $86.4 \mathrm{emu} \mathrm{cm}{ }^{-3}$ for the films prepared at 20 and $10 \mathrm{~W}$, respectively. This could be explained by the presence of a small quantity of monoxide, which does not contribute as strongly to the magnetization of the film as the ferrimagnetic spinel phase.

Some experiments carried out at argon pressures increasing from 0.5 to $1.5 \mathrm{~Pa}$ show also that this modification of sputtering conditions leads to a decrease in magnetization measured at 30 kOe. Moreover, at higher argon pressures, the X-ray diffraction patterns reveal the formation of monoxide in addition to the spinel phase.

When the argon pressure and the RF power density were fixed at $0.5 \mathrm{~Pa}$ and $20 \mathrm{~W}$, respectively, the films obtained display the X-ray diffraction pattern of a pure spinel phase and have high magnetization. They also display the same Raman spectrum as that of a pure $\mathrm{Co}_{1.7} \mathrm{Fe}_{1.3} \mathrm{O}_{4}$ spinel powder (Fig. 3). Similar results were obtained at $0.5 \mathrm{~Pa}$ and $10 \mathrm{~W}$ but the deposition rate is lower in this case. The sputtering conditions selected for the preparation of the samples studied in

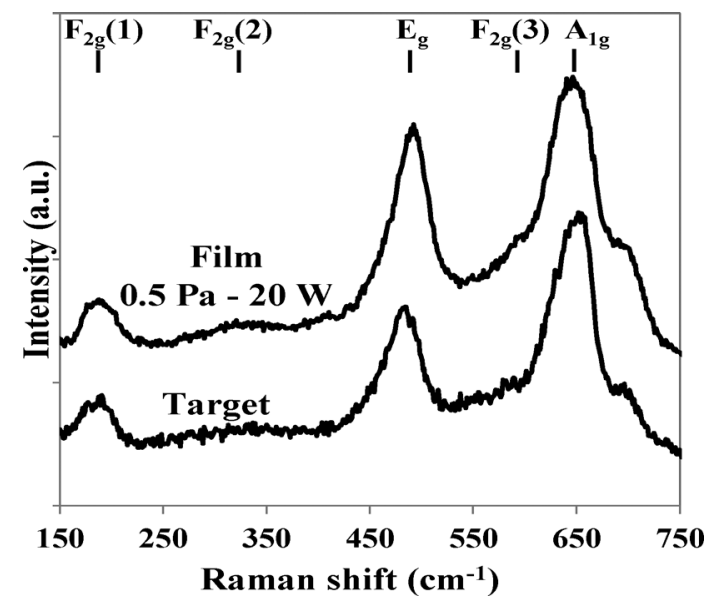

Fig. 3 Raman spectra of films deposited at $0.5 \mathrm{~Pa}$ and $20 \mathrm{~W}$. the following section, dedicated to the study of the thermal stability of the films, were then $0.5 \mathrm{~Pa}$ and $20 \mathrm{~W}$. The microstructure of such films is made of well crystallized small columns of about 20 to $30 \mathrm{~nm}$ in diameter (Fig. 4). The Ra roughness of the films, measured by atomic force microscopy, is close to $2 \mathrm{~nm}$.

\section{Annealed films}

As was pointed out in the Introduction, the $\mathrm{Co}_{x} \mathrm{Fe}_{3-x} \mathrm{O}_{4}$ solid solutions acquired so far, at about 900 to $950{ }^{\circ} \mathrm{C}$ and then quenched to room temperature, are not stable in the miscibility gap (from RT to about $875{ }^{\circ} \mathrm{C}$ ). The $\mathrm{Co}_{1.7} \mathrm{Fe}_{1.3} \mathrm{O}_{4}$ RF-sputtered films of this work were not treated at such temperatures because the sputtering process of oxides generally leads to temperatures lower than $200{ }^{\circ} \mathrm{C}$ on the substrate surface. However, due to thermodynamic reasons, they also have to be transformed in the miscibility gap even if different parameters, such as mechanical stress and crystallite size, could influence the mechanism and the speed of transformation as observed for samples studied so far. Their thermal stability inside the miscibility gap was then carefully studied, mainly at quite low temperatures compatible with the use of ordinary glass substrates.

The first experiments were carried out in an X-ray diffractometer equipped with a heating chamber. Fig. 5 shows that the peaks corresponding to the spinel structure are not clearly modified by these heating conditions apart from a slight shift of the Bragg position towards low 2 theta angles due to the thermal expansion. However, broadening of peaks is observed from the powder diffraction patterns recorded at $600{ }^{\circ} \mathrm{C}$ and higher temperatures. Some other diffractograms were recorded at $600{ }^{\circ} \mathrm{C}$ for different durations (Fig. 6). Above about 5 hours of hold time, some peaks started to split (i.e. (440) for instance). This split indicates that the initial single phased film is transformed into two spinel phases. An iron-rich phase and another phase rich in cobalt, with crystalline parameters respectively greater and smaller than the initial phase, grew progressively according to the characteristic process of the spinodal decomposition. ${ }^{11}$ After cooling to room temperature, the sample remained two-phased.

a)

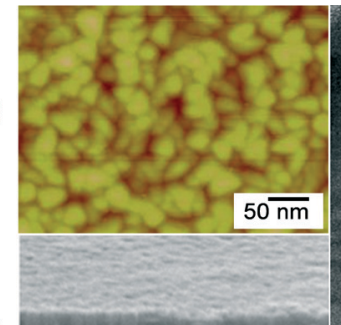

b)

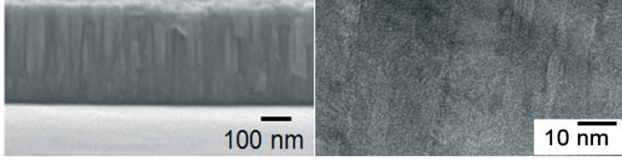

c)

Fig. 4 Microstructure of films deposited at $0.5 \mathrm{~Pa}$ and $20 \mathrm{~W}$ : the AFM planar view (4a) and the SEM (4b) and TEM (4c) cross section views. 


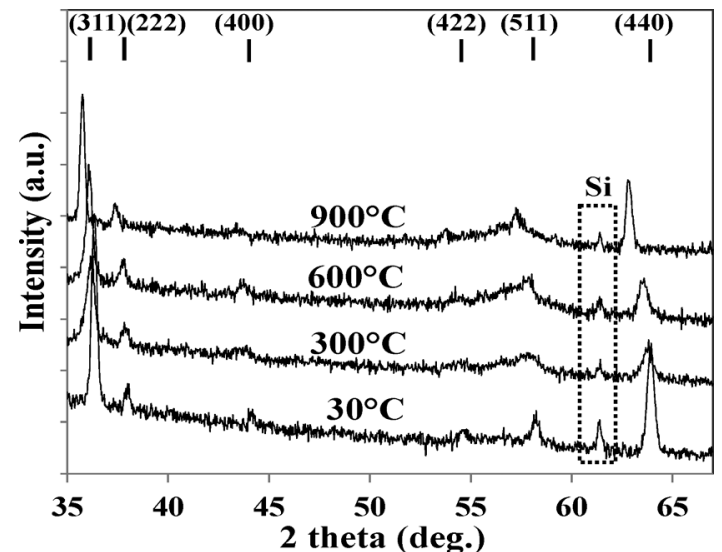

Fig. 5 XRD patterns registered at different temperatures of films deposited at $0.5 \mathrm{~Pa}$ and $20 \mathrm{~W}$.

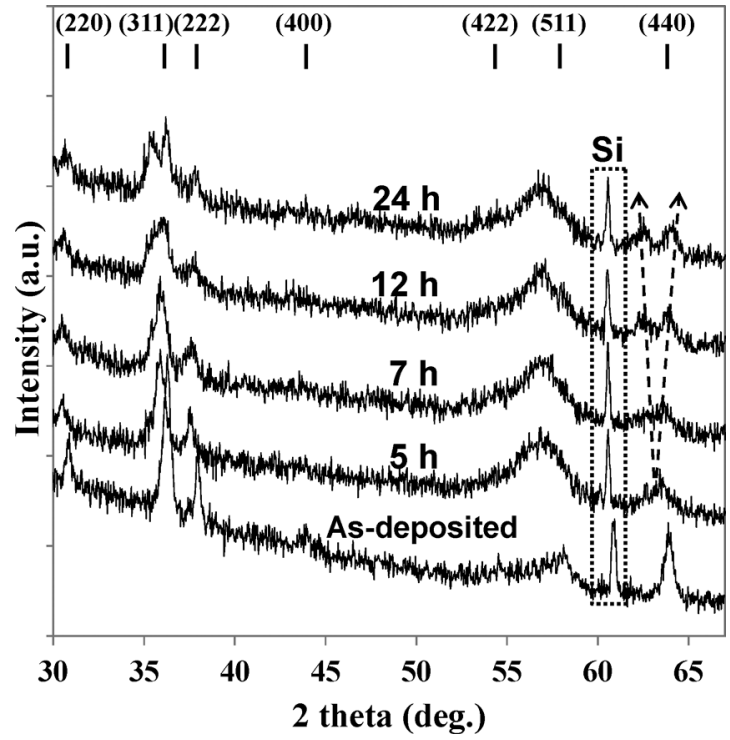

Fig. 6 XRD patterns registered at $600{ }^{\circ} \mathrm{C}$ of films deposited at $0.5 \mathrm{~Pa}$ and $20 \mathrm{~W}$ on a silicon substrate.

The structural changes of $\mathrm{Co}_{1.7} \mathrm{Fe}_{1.3} \mathrm{O}_{4}$ films were also studied by Raman spectroscopy. The $\mathrm{Co}_{1.7} \mathrm{Fe}_{1.3} \mathrm{O}_{4}$ film deposited on the quartz was heated in a conventional furnace at $600{ }^{\circ} \mathrm{C}$ for increasing durations. Raman spectra revealed the main peaks related to the spinel oxides, already identified in previous studies. ${ }^{16-18}$ They are also changing with the duration of the heat treatment (Fig. 7). The main change, especially above 6 hours, is the very strong growth of the $F_{2 g}(1)$ and $A_{1 g}$ peaks. The emergence of low-intensity $F_{2 g}(2)$ and $F_{2 g}(3)$ peaks must also be reported. X-ray diffraction results show that the spinodal decomposition is only observed after more than 5 hours of treatment. This is in good accordance with XRD analysis results which show that the spinodal decomposition is only observed after more than 5 hours of treatment.

To understand such changes, it is interesting to have a look at the Raman spectra of cobalt-rich $\left(\mathrm{Co}_{2.46} \mathrm{Fe}_{0.54} \mathrm{O}_{4}\right)$

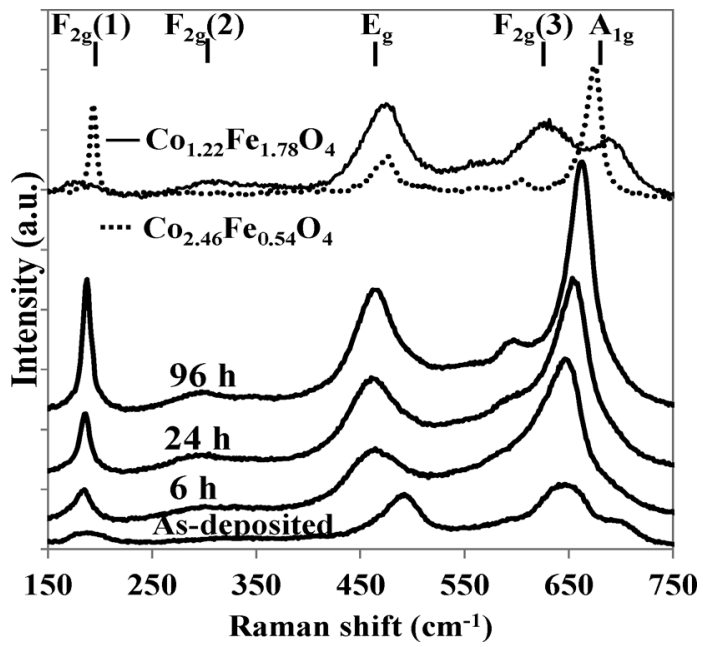

Fig. 7 Raman spectra of films deposited at $0.5 \mathrm{~Pa}$ and $20 \mathrm{~W}$ and annealed at $600{ }^{\circ} \mathrm{C}$ for different annealing times compared with Raman spectra of $\mathrm{Co}_{1.22} \mathrm{Fe}_{1.78} \mathrm{O}_{4}$ (iron rich spinel) and $\mathrm{Co}_{2.46} \mathrm{Fe}_{0.54} \mathrm{O}_{4}$ (cobalt rich spinel).

and iron-rich $\left(\mathrm{Co}_{1.22} \mathrm{Fe}_{1.78} \mathrm{O}_{4}\right)$ spinel powders as reference samples (Fig. 7).

These powders have chemical compositions very close to those $\left(\mathrm{Co}_{2.69} \mathrm{Fe}_{0.31} \mathrm{O}_{4}\right.$ and $\left.\mathrm{Co}_{1.16} \mathrm{Fe}_{1.84} \mathrm{O}_{4}\right)$ obtained after complete transformation of the $\mathrm{Co}_{1.7} \mathrm{Fe}_{1.3} \mathrm{O}_{4}$ cobaltite. ${ }^{19}$ In other words, they have very similar compositions to those which limit the miscibility gap at low temperatures. The Raman spectra of these powders are quite different. Very well defined peaks of $F_{2 g}(1)$ and $A_{1 g}$ and, to a lesser extent, $F_{2 g}(1)$ are observed for the Co-rich phase. These can be ascribed to a high content of $\mathrm{Co}^{2+}$ ions in tetrahedral sites $\left(\mathrm{F}_{2 \mathrm{~g}}(1)\right.$ peak) and to a high content of $\mathrm{Co}^{3+}$ ions in octahedral sites $\left(\mathrm{A}_{1 \mathrm{~g}}\right.$ peak). According to ref. 19 the structural formula of the Co-rich phase is indeed:

$$
\mathrm{Co}_{1}{ }^{2+}\left[\mathrm{Co}_{1.46}{ }^{3+} \mathrm{Fe}_{0.54}{ }^{3+}\right] \mathrm{O}_{4}{ }^{2-}
$$

(cations outside and inside the brackets are located in the tetrahedral and octahedral sites, respectively). By contrast, the small $F_{2 g}(2)$ peak is characteristic of the iron-rich phase. It is then clear that the superposition of such spectra leads to a spectrum similar to that observed after a long heat treatment of the $\mathrm{Co}_{1.7} \mathrm{Fe}_{1.3} \mathrm{O}_{4}$ film. The growth of the $\mathrm{F}_{2 \mathrm{~g}}(1)$ and $A_{1 g}$ peaks and the emergence of low-intensity $F_{2 g}(2)$ and $F_{2 g}(3)$ peaks after heat treatments are so simply explained by the formation of cobalt-rich and iron-rich phases.

According to previous results, ${ }^{19}$ the transformation of $\mathrm{Co}_{1.7} \mathrm{Fe}_{1.3} \mathrm{O}_{4}$ powders by spinodal decomposition or nucleation and growth does not lead to a strong difference in the average number of oxygen anions surrounding each cation in the spinel lattices of the material. The real change is that the cations are located in two separated phases in such a manner that some cations are "concentrated" in a sub-lattice in a given spinel phase. For instance, the formation of a cobalt-rich phase, resulting from the spinodal transformation, concentrates $100 \%$ of $\mathrm{Co}^{2+}$ ions and $75 \%$ of $\mathrm{Co}^{3+}$ ions in its tetrahedral and 
octahedral sites, respectively (see formula (1)). The contribution to the Raman spectra of such a phase, which is significantly different than the iron-rich phase in which the cobalt ions are "diluted" in the two sub-lattices, thus becomes clearly visible. Raman spectroscopy is then very sensitive to the formation of a new spinel phase very rich in cobalt ions.

No clear contrast between the two phases formed by spinodal transformation at $600{ }^{\circ} \mathrm{C}$ for 24 hours was highlighted. Local chemical analyses were also unable to reveal the phases individually as shown by the homogeneous distribution of the iron and cobalt species in the cross section STEM view (Fig. 8a). A complete segregation occurs however after a much longer annealing time. For instance, a sample heat treated in air at $600{ }^{\circ} \mathrm{C}$ for 96 hours clearly displays cobalt rich and iron rich regions of about $50 \mathrm{~nm}$ in diameter (Fig. 8b). The random distribution of the two phases in these regions along and perpendicular to the columns reveals however that the spinodal transformation is replaced by a nucleation and growth process for such a very long time of treatment at $600{ }^{\circ} \mathrm{C}$.

In order to achieve spinodal decomposition at moderate temperature, annealing treatment at $450{ }^{\circ} \mathrm{C}$ was also carried out. The annealing of the films at $4500^{\circ} \mathrm{C}$ increases a little bit the average grain size. Indeed, atomic force microscopy reveals that the mean diameter of the grains changes from 30 to about $50 \mathrm{~nm}$. After 24 hours of treatment at $450{ }^{\circ} \mathrm{C}$, there is no clear change in the X-ray diffraction patterns. A careful examination of the patterns shows however a very small peak broadening. This is in contradiction to the increase of the size of the grains. Coarser grains would suggest an improvement of crystallization, revealed by narrower diffraction peaks. The peak broadening could then reveal the beginning of the spinodal decomposition.

Raman spectroscopy is however more informative (Fig. 9). After only 5 minutes of treatment at $450{ }^{\circ} \mathrm{C}$, the $\mathrm{F}_{2 \mathrm{~g}}(1)$ and $A_{1 g}$ peaks as well as the $F_{2 g}(3)$ peak grew significantly in a manner similar to that observed for films decomposed at $600{ }^{\circ} \mathrm{C}$. This growth continued for longer annealing times. It seems reasonable then to conclude that the spinodal decomposition starts a few minutes after the $\mathrm{Co}_{1.7} \mathrm{Fe}_{1.3} \mathrm{O}_{4}$ is

a)
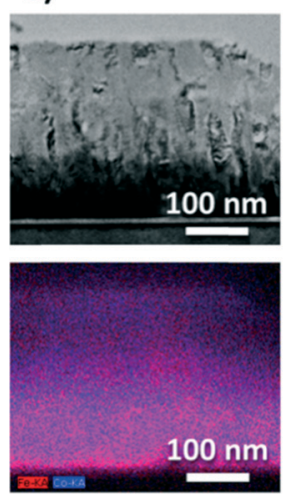

b)
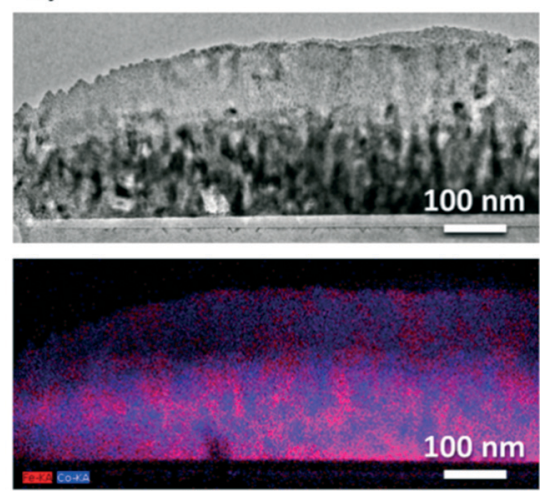

Fig. 8 Cross section STEM micrographs and corresponding EDS maps obtained using iron (red) and cobalt (blue) $\mathrm{K} \alpha$ of the films annealed at $600{ }^{\circ} \mathrm{C}$ for $24 \mathrm{~h} \mathrm{(a)}$ and $96 \mathrm{~h}(\mathrm{~b})$.

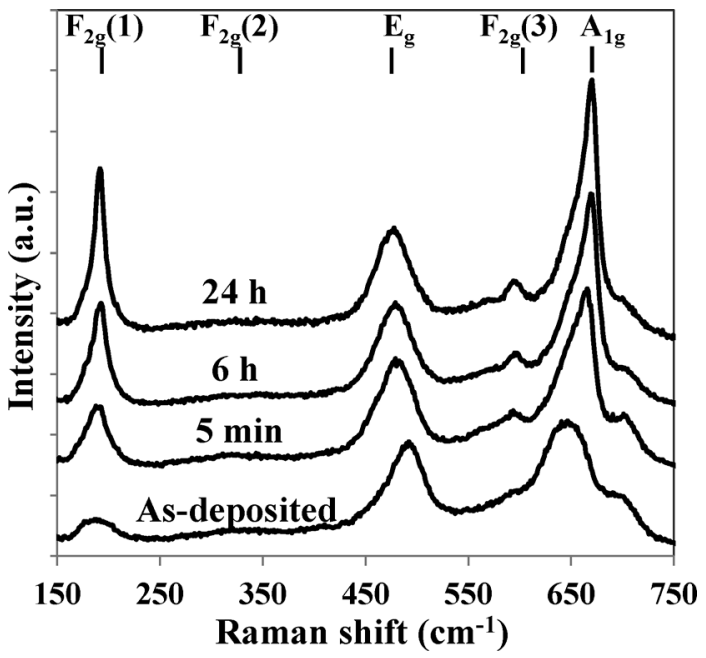

Fig. 9 Raman spectra of films deposited at $0.5 \mathrm{~Pa}$ and $20 \mathrm{~W}$ and annealed several times at $450^{\circ} \mathrm{C}$.

heated at $450{ }^{\circ} \mathrm{C}$, even if no clear change in the X-ray diffraction patterns is observed. The changes observed through Raman spectroscopy could be the first step of spinodal decomposition already described by Harrison and Putnis ${ }^{20}$ which corresponds to the development of low-amplitude sinusoidal fluctuation of compositions. The gathering of cobalt ions in a small region could make its detection by Raman spectroscopy possible, but the gradual variation of the composition induced by this first step of the spinodal decomposition could make the characterization by X-ray diffraction difficult. Just a small peak broadening could be expected from this technique.

Treatments at temperatures even lower than $450{ }^{\circ} \mathrm{C}$ were also carried out. It was very surprising to see that after only 2 hours at $300{ }^{\circ} \mathrm{C}$, the Raman spectra of $\mathrm{Co}_{1.7} \mathrm{Fe}_{1.3} \mathrm{O}_{4}$ films begin to resemble the shape of decomposed cobaltites spectra (Fig. 10). This evolution is obviously more pronounced for treatments at higher temperatures. Fig. 11 clearly illustrates the initiation of decomposition for mild heating and its progress for more energetic treatments. The $F_{2 g}(1)$ peak intensity, normalized by that of the $E_{g}$ peak, which remains approximately constant along the treatments, grows regularly and significantly with the heating temperature and time.

Electron exchanges between $\mathrm{Mn}^{+}$and $\mathrm{M}^{(n+1)+}$ cations located in the same sub-lattice induce semi-conducting properties in spinel oxides. ${ }^{21} \mathrm{Co}_{1.7} \mathrm{Fe}_{1.3} \mathrm{O}_{4}$ is thus a semiconductor because its structural formula is close to

$$
\mathrm{Co}_{0.61}{ }^{2+} \mathrm{Fe}_{0.39}{ }^{3+}\left[\mathrm{Co}_{0.39}{ }^{2+} \mathrm{Co}_{0.73}{ }^{3+} \mathrm{Fe}_{0.88}{ }^{3+}\right] \mathrm{O}_{4}{ }^{2-}
$$

according to ref 19. However, due to the high activation energy of the electronic exchange for the $\mathrm{Co}^{2+} / \mathrm{Co}^{3+}$ couples, ${ }^{22,23}$ the electrical resistivity of such a material is quite high at room temperature but decreases strongly at higher temperatures. The electrical resistivities of the as-sputtered and heat treated $\mathrm{Co}_{1.7} \mathrm{Fe}_{1.3} \mathrm{O}_{4}$ samples were then studied at $250{ }^{\circ} \mathrm{C}$, to make the 


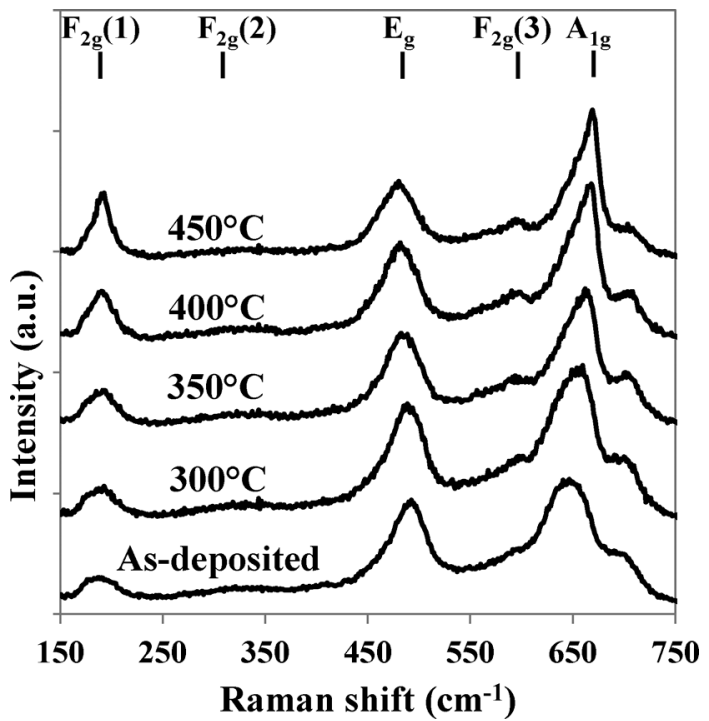

Fig. 10 Raman spectra of films deposited at $0.5 \mathrm{~Pa}$ and $20 \mathrm{~W}$ and annealed for $2 \mathrm{~h}$ at different temperatures.

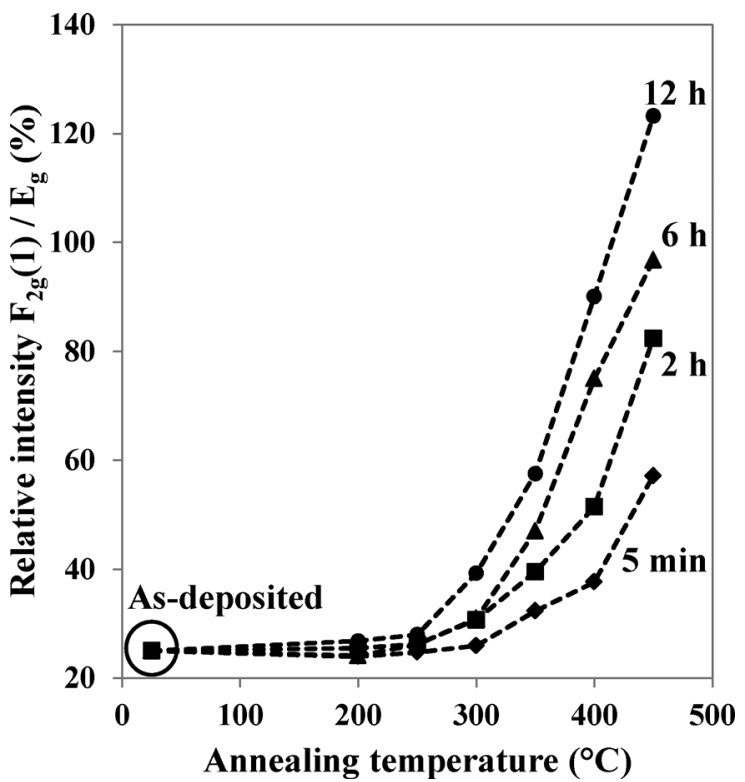

Fig. 11 The evolution of the $F_{2 g}(1)$ Raman peak relative intensity of films deposited at $0.5 \mathrm{~Pa}$ and $20 \mathrm{~W}$ versus annealing temperature and time.

measurements possible in our experimental set-up. A quite high activation energy, close to $0.48 \mathrm{eV}$, was measured in agreement with the bibliographic data. ${ }^{22,23}$ On the other hand, Fig. 12 shows that the resistivity of the films increases almost linearly with the time of annealing at $450{ }^{\circ} \mathrm{C}$. This clearly demonstrates significant changes in the material at this moderate temperature of treatment. According to ref. 19 at the end of the transformation of $\mathrm{Co}_{1.7} \mathrm{Fe}_{1.3} \mathrm{O}_{4}$ in the miscibility gap, the cobalt-rich phase formed is an insulator because it has no more $\mathrm{Co}^{2+}$ and $\mathrm{Co}^{3+}$ ions on the same sub-lattice. The iron-rich phase $\left(\mathrm{Co}_{1.16} \mathrm{Fe}_{1.84} \mathrm{O}_{4}\right)$, which is also

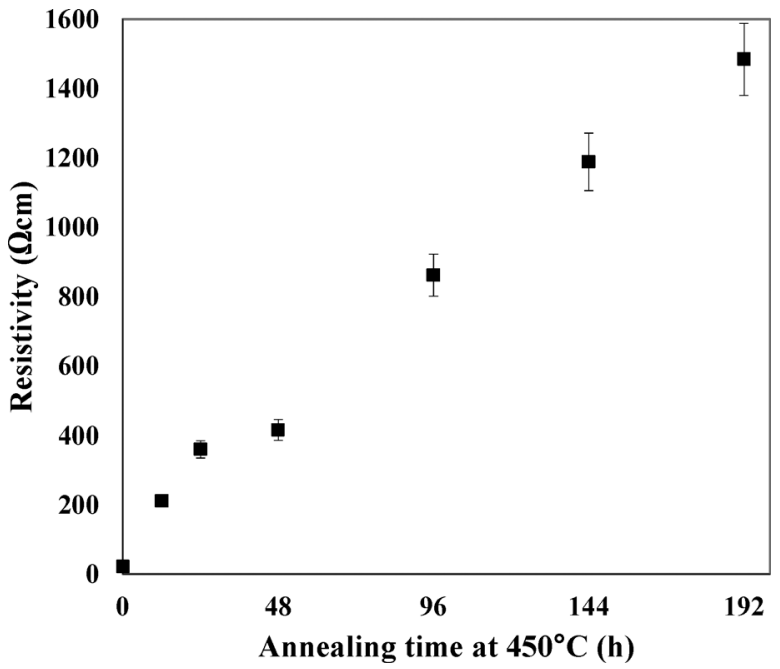

Fig. 12 Electrical measurements at $250^{\circ} \mathrm{C}$ of films deposited at $0.5 \mathrm{~Pa}$ and $20 \mathrm{~W}$ and annealed at $450^{\circ} \mathrm{C}$ for different durations.

created, is however a semiconductor. However, its structural formula is close to

$$
\mathrm{Co}_{0.30}{ }^{2+} \mathrm{Fe}_{0.70}{ }^{3+}\left[\mathrm{Co}_{0.70}{ }^{2+} \mathrm{Co}_{1.16}{ }^{3+} \mathrm{Fe}_{1.14}{ }^{3+}\right] \mathrm{O}_{4}{ }^{2-}
$$

which shows that the number of $\mathrm{Co}^{2+} / \mathrm{Co}^{3+}$ couples is much lower than that of the initial single phase $\mathrm{Co}_{1.7} \mathrm{Fe}_{1.3} \mathrm{O}_{4}$ (see structural formula (2)). The spinodal decomposition of the latter necessarily leads to a progressive increase in resistivity. This is in agreement with the results of the electrical measurements shown in Fig. 12. The combination of the results coming from Raman spectroscopy and electrical measurements then seems to prove the beginning of the spinodal transformation, after heat treatments at very moderate temperatures for quite a short time of annealing.

\section{Conclusion}

Thin films of $\mathrm{Co}_{1.7} \mathrm{Fe}_{1.3} \mathrm{O}_{4}$ were prepared for the first time by RF sputtering on a substrate at room temperature. Pure as-deposited samples are made of small crystallites of about a few tens of nanometers. Because they have a composition inside the miscibility gap of the phase diagram of $\mathrm{CoFe}_{2} \mathrm{O}_{4}-\mathrm{Co}_{3} \mathrm{O}_{4}$, their thermal stability was studied. It was shown that RF sputtered $\mathrm{Co}_{1.7} \mathrm{Fe}_{1.3} \mathrm{O}_{4}$ films are not stable at $600{ }^{\circ} \mathrm{C}$ as for cobaltites of a similar composition already prepared at high temperature. More original results were obtained however. It was demonstrated using mainly Raman spectroscopy and electrical measurements that $\mathrm{Co}_{1.7} \mathrm{Fe}_{1.3} \mathrm{O}_{4}$ films can be partially transformed at quite low temperatures, ranging from 300 to $450{ }^{\circ} \mathrm{C}$, and after quite a short time of annealing. This partial transformation is a first step of spinodal decomposition. From the present work it can then be concluded that the preparation of thin films structured by spinodal transformation could be obtained at temperatures 
compatible with the use of cheap substrates such as conventional glass slides or silicon wafers.

\section{Acknowledgements}

Thi Mai Anh Bui wishes to thank the Vietnamese Government Scholarship (project 322) of the Vietnam Ministry of Education and Training and the support of Carnot Institute CIRIMAT for her PhD grant.

\section{Notes and references}

1 J. W. Cahn and J. E. Hilliard, J. Chem. Phys., 1958, 28, 258-267.

2 M. G. M. Miranda, E. Esteves-Rams, G. Martinez and M. N. Baibich, Phys. Rev. B: Condens. Matter Mater. Phys., 2003, 68, 01443.

3 M. G. M. Miranda, A. T. da Rosa, R. Hinrichs, U. Golla-Schindler, A. B. Antunes, G. Martinez, E. Esteves-Rams and M. N. Baibich, Phys. B, 2006, 384, 175-178.

4 A. Hutten, D. Sudfeld, K. Wojcrykowski, P. Jutzi and G. Reiss, J. Magn. Magn. Mater., 2003, 262, 23-31.

5 S. A. Nikitov, P. Tailhades and C. S. Tsai, J. Magn. Magn. Mater., 2001, 236, 320-330.

6 Y. V. Gulyaev, S. A. Nikitov, L. V. Zhivotovskii, A. A. Klimov, P. Tailhades, L. Presmanes, C. Bonningue, C. S. Tsai, S. L. Vysotskii and Y. A. Filimonov, JETP Lett., 2003, 77, 567-570.

7 J. Robin, Ann. Chim, 1955, 10, 389-412.

8 M. Takahashi and M. E. Fine, J. Am. Ceram. Soc., 1970, 53, 633-634.
9 M. Takahashi, J. R. C. Guimares and M. E Fine, J. Am. Ceram. Soc., 1971, 54, 291-295.

10 P. J. Murray and J. W. Linnett, J. Phys. Chem. Solids, 1976, 37, 619-624.

11 S. Hirano, T. Yogo, K. Kikuta, E. Asai, K. Sugiyama and H. Yamamoto, J. Am. Ceram. Soc., 1993, 76, 1788-1792.

12 K. J. Kim, J. H. Lee and C. S Kim, J. Korean Phys. Soc., 2012, 61, 1274-1278.

13 H. Le Trong, A. Barnabé, L. Presmanes and P. Tailhades, Solid State Sci., 2008, 10, 550-556.

14 I.-H. Jung, S. Decterov, A. D. Pelton, H.-M. Kim and Y.-B. Kang, Acta Mater., 2004, 52, 507-519.

15 M. Takahashi and M. E. Fine, J. Appl. Phys., 1972, 43, 4205-4216.

16 H. Shirai, Y. Morioka and I. Nakagawa, J. Phys. Soc. Jpn., 1982, 51, 592-597.

17 V. G Hadjiev, M. N. Iliev and I. V. Vergilov, J. Phys. Chem., 1988, 21, 199-201.

18 P. Chandramohan, M. P. Srinivasan, S. Velmurugan and S. V. Narashimhan, J. Solid State Chem., 2011, 184, 89-96.

19 H. Le Trong, L. Presmanes, E. De Grave, A. Barnabé, C. Bonningue and P. Tailhades, J. Magn. Magn. Mater., 2013, 334, 66-73.

20 R. J. Harrison and A. Putnis, Surveys in Geophysics, 1999, 19, 461-520.

21 E. J. W. Verwey and P. W. Haayman, Phys. A, 1941, 8, 979-987.

22 G. H. Jonker, J. Phys. Chem. Solids, 1959, 9, 165.

23 P. A. Cox, Electronic structure and chemistry of solids, Oxford Science Publications, 1987, p. 184. 